\title{
O Impacto do Pronaf sobre a Sustentabilidade da Agricultura Familiar, Geração de Emprego e Renda no Estado do Ceará
}

\author{
Nagilane Parente Damasceno ${ }^{1}$ \\ Ahmad Saeed Khan ${ }^{2}$ \\ Patrícia Verônica Pinheiro Sales Lima ${ }^{3}$
}

Resumo: O estudo analisa a contribuição do Pronaf (Programa Nacional de Fortalecimento da Agricultura Familiar) para o desenvolvimento sustentável da agricultura familiar no estado do Ceará. Para tal finalidade, foi realizado um levantamento de dados primários nos municípios de Baturité, Igutau e Quixadá. Foram aplicados 30 questionários em cada município, sendo 15 para beneficiários e 15 para não beneficiários, totalizando 90 questionários. Através do cálculo do Índice de Sustentabilidade (IS), do emprego agropecuário por hectare cultivado e da renda agropecuária por hectare cultivado foi possível mensurar o nível de desenvolvimento sustentável dos agricultores familiares beneficiários e não beneficiários, e o efeito do programa sobre a renda e o emprego. Com base em análise descritiva e na aplicação dos testes t de Student, Qui-Quadrado e U de Mann-Whitney foram realizadas comparações entre os grupos de agricultores familiares selecionados. Tanto os agricultores familiares beneficiários quanto aqueles não beneficiários apresentaram baixo nível de sustentabilidade. O Pronaf teve impacto positivo, mas não significante sobre a geração de renda, e efeito positivo sobre o emprego.

Palavras-chave: Pronaf, sustentabilidade, agricultura familiar, renda, emprego.

Abstract: This study analyzes the contribution of Pronaf (National Program for Strengthening of Family Farming) for the sustainable development of family farming in the Ceara state. For this purpose, primary data was obtained through the application of 15 questionnaires to beneficiaries and the equal number to non-beneficiaries in Baturite, Iguatu and Quixada counties, totaling 90 questionnaires. The sustainability index,

1 Economista, Mestre em Economia Rural pela Universidade Federal do Ceará.

2 PhD em Economia Agrícola e Recursos Naturais, Professor da Universidade Federal do Ceará, Bolsista CNPq.

3 Doutora em Economia Aplicada, Professora da Universidade Federal do Ceará, Bolsista CNPq. 
130 - O Impacto do Pronaf sobre a Sustentabilidade da Agricultura Familiar, Geração de Emprego e Renda no Estado do Ceará

employment and farm income per cultivated hectare were calculated to measure the impact of the program on the sustainable development, generation of income and employment on family farms of beneficiaries. Based on the descriptive analysis and the application of the t Student test, Chi-Square test and Mann-Whitney U test, comparisons between the selected groups of family farming were promoted. Results showed that the beneficiaries and non-beneficiaries have a low sustainability level. Pronaf had a positive impact, but not significant on farm income generation, and positive effect on the creation of employment.

Key-words: Pronaf, sustainability, family farming, income, employment.

Classificação JEL: Q16, Q18.

\section{Introdução}

A agricultura familiar exerce um papel fundamental no desenvolvimento social e no crescimento equilibrado do País. Os milhões de pequenos produtores que compõem a agricultura familiar fazem dela um setor em expansão e de vital importância para o Brasil. Todos os anos, a agricultura familiar movimenta bilhões de reais no País, produzindo a maioria dos alimentos que são consumidos nas mesas brasileiras. Além disso, contribui para a criação de empregos, geração e distribuição de renda e diminuição do êxodo rural.

De modo a promover o acesso democrático aos recursos produtivos, reduzir as desigualdades e melhorar o bem-estar das famílias inseridas no setor rural, o governo tem implementado diversos mecanismos de fomento à produção, combate à fome e geração de emprego e renda.

Nesse sentido, a primeira iniciativa concreta ocorreu em 1996, com a instituição do Pronaf (Programa Nacional de Fortalecimento da Agricultura Familiar), ampliado a partir de 2004. Com o programa, os agricultores familiares conquistaram maior atenção do governo federal e ações específicas destinadas a promover a melhoria das suas condições de vida. Até então, os instrumentos de apoio destinados a esta categoria estavam divididos em diversas políticas setoriais (política agrícola, programas de colonização, política de combate à pobreza rural etc.) e em categorias operacionais (BUAINAIN, 2006).

A partir de então, o Pronaf passa a ser considerado um importante instrumento de Estado ao possibilitar a captação de capital financeiro e humano, o que pode viabilizar a obtenção da sustentabilidade dos agricultores e de suas famílias. Com base nos princípios de participação, parceria, descentralização e gestão social, o Pronaf tem como alicerce o amadurecimento do exercício da democracia, o que ocorre, principalmente, por meio dos Conselhos Municipais de Desenvolvimento Rural Sustentável (CMDRS), onde o agricultor familiar e os diversos representantes dos segmentos sociais dos municípios debatem 
seus problemas e apontam as alternativas de solução, a partir de suas próprias experiências, necessidades e prioridades (LIMA NETO, 1999).

Os relatórios institucionais recentes do Pronaf destacam que este foi,

[...] desde o início, concebido e executado como um programa de apoio ao desenvolvimento local, e não somente como meio de levar crédito aos agricultores e enviar recursos a municípios carentes: tão importante quanto o crédito, os recursos e a formação dos agricultores e dos técnicos, é a integração dessas políticas, que se consegue, antes de tudo, pelo esforço das organizações e do estimulo à coordenação entre os atores econômicos privados, organizações associativas e diferentes esferas do governo (PRONAF, 2002).

Para a safra 2007/2008, o governo federal colocou à disposição dos agricultores familiares de todo o País R\$ 12 bilhões em financiamento rural do Pronaf, com a meta de alcançar 2,2 milhões de famílias (MDA, 2007). Já o Plano Safra 2008/2009 lançou significativas alterações no Pronaf, além de disponibilizar R\$ 13 bilhões para a agricultura familiar (MDA, 2008).

Com o surgimento do Pronaf, o discurso a favor da sustentabilidade se fez presente. No entanto, a realidade tem mostrado que este programa ainda deixa muito a desejar, tendo em vista que predomina o simples incentivo à produtividade e supersafras, sem refutação dos processos produtivos vigentes no País (ALTAFIN, 2003).

Embora o volume de crédito disponibilizado pelo governo federal e a quantidade de famílias beneficiadas aumentem a cada ano, não há um consenso a respeito dos impactos do programa em relação ao crescimento da renda e à melhoria do padrão de vida dos agricultores. Algumas pesquisas realizadas com o intuito de avaliar o Pronaf mostraram que o programa apresenta efeitos positivos. No entanto, outros estudos mostraram que o programa apresenta resultados negativos em termos de impacto, além de piorar a situação dos beneficiários em relação à dos não beneficiários (GUANZIROLI, 2007).

A democratização das políticas públicas representa um caminho promissor para a construção de um desenvolvimento que seja sustentável não só do ponto de vista ambiental, social e econômico, mas também político. Apesar da importância da agricultura familiar para o desenvolvimento local, regional e nacional, e dos elevados custos de operacionalização do Pronaf, poucos estudos foram realizados para avaliar o programa no que diz respeito à contribuição para o desenvolvimento sustentável dos agricultores familiares, assim como ao seu impacto na geração de emprego e renda. Um estudo com esse objetivo pode oferecer subsídio ao governo federal para verificar se as políticas que pretendem melhorar o bem-estar dos agricultores familiares estão funcionando adequadamente. 
132 - O Impacto do Pronaf sobre a Sustentabilidade da Agricultura Familiar, Geração de Emprego e Renda no Estado do Ceará

\subsection{Objetivos}

Os objetivos do estudo são:

- Mensurar o desenvolvimento sustentável dos agricultores familiares selecionados;

- Verificar as principais fontes de renda dos agricultores familiares beneficiários e não beneficiários do Pronaf;

- Verificar a diferença na renda agropecuária e não agropecuária dos beneficiários e não beneficiários do Pronaf;

- Verificar a diferença na quantidade de mão de obra empregada pelos beneficiários em relação aos não beneficiários do Pronaf.

\section{Referencial Teórico}

\subsection{Desenvolvimento Sustentável}

A idéia de sustentável indica algo capaz de ser suportável, duradouro e conservável, apresentando imagem de continuidade. Trata-se da emergência de um paradigma, voltado para a orientação dos processos, ou ainda de uma reavaliação dos relacionamentos da economia e da sociedade com a natureza e do Estado com a sociedade civil.

O conceito de desenvolvimento sustentável tem dimensões ambientais, econômicas, sociais, políticas e culturais, o que necessariamente traduz várias preocupações: com o presente e o futuro das pessoas; com a produção e o consumo de bens e serviços; com as necessidades básicas de subsistência; com os recursos naturais e o equilíbrio ecossistêmico; com as práticas decisórias e a distribuição de poder; e com os valores pessoais e a cultura. O conceito é abrangente e integral $\mathrm{e}$, necessariamente, distinto, quando aplicado às diversas formações sociais e realidades históricas (JARA, 1996).

O que é sustentável nos países desenvolvidos da pós-modernidade globalizada não é necessariamente sustentável para os países dependentes e pobres. A sustentabilidade diz respeito a um significado dinâmico e flexível, centrado no respeito à vida. A redução da pobreza, a satisfação das necessidades básicas, a melhoria da qualidade de vida da população, o resgate da equidade e o estabelecimento de uma forma de governo que garanta a participação social nas decisões são condições essenciais para que o processo de desenvolvimento seja julgado como sustentável (JARA, 1996).

O desenvolvimento sustentável refere-se aos processos de transformação socioeconômica e institucional que intencionam assegurar a satisfação das necessidades básicas da população e a equidade social, tanto no presente quanto no futuro, promovendo oportunidades de bem-estar econômico que sejam compatíveis com as circunstâncias ecológicas de longo prazo (SIENA, 2002 apud RABELO, 2008). 
O conceito de desenvolvimento sustentável teve origem a partir do Clube de Roma, formado por intelectuais e empresários que não eram militantes ecologistas. Por intermédio dele foram produzidos os primeiros estudos científicos a respeito da preservação ambiental, apresentados entre 1972 e 1974.

Tais estudos relacionavam quatro grandes questões que deveriam ser solucionadas para que se alcançasse a sustentabilidade: o controle do crescimento populacional, o controle do crescimento industrial, a insuficiência da produção de alimentos e o esgotamento dos recursos naturais.

Essas discussões se ampliaram e o movimento ambientalista foi se formando e ganhando importância no plano internacional, sendo que, em 1972, foi realizada a primeira Conferência das Nações Unidas sobre o Meio Ambiente, em Estocolmo (Suécia), na qual foram destacados 27 princípios norteadores da relação homem-natureza.

Este conjunto de princípios denunciava, em grande parte, a responsabilidade do subdesenvolvimento pela degradação ambiental e estabelecia a base teórica para a expressão desenvolvimento sustentável.

Em 1987, a Comissão Mundial para o Meio Ambiente e Desenvolvimento, presidida pela primeira ministra da Noruega, Gro Harlem Brundtland, elaborou um documento denominado "Nosso Futuro Comum", segundo o qual os governos signatários se comprometiam a promover o desenvolvimento econômico e social em conformidade com a preservação ambiental.

Nesse documento, que também ficou conhecido como Relatório Brundtland, foram apresentados a definição oficial do conceito de desenvolvimento sustentável e os métodos para enfrentar a crise pela qual o mundo passava. $\mathrm{O}$ referido documento busca um mundo mais humano e enfatiza que a redução da pobreza é a precondição para um desenvolvimento ambientalmente justo.

Está implícita também a idéia de alcançar um desenvolvimento contínuo sem exaurir os recursos naturais, ou seja, o raciocínio sobre o uso racional do capital ecológico, evitando causar prejuízos para a comunidade como um todo.

A proposta de desenvolvimento sustentável teve a vantagem de denunciar como são inviáveis os atuais modelos de desenvolvimento que seguem padrões de crescimento econômico não sustentáveis no longo prazo. Além disso, este conceito prevê que o crescimento econômico não pode ocorrer sem a superação da pobreza e o respeito aos limites ecológicos.

São esses quatro parâmetros - preservação da natureza, eliminação da pobreza, crescimento econômico e garantia de existência das gerações futuras -, concebidos em conjunto, que conferem a possibilidade de alcançar uma sustentabilidade que seja global.

A definição mais consagrada e simplificada de desenvolvimento sustentável é apresentada no relatório Nosso Futuro Comum, da Comissão Brundtland, em 1987:

[...] aquele que satisfaz as necessidades do presente sem comprometer a capacidade das gerações futuras satisfazerem as suas próprias neces- 
134 - O Impacto do Pronaf sobre a Sustentabilidade da Agricultura Familiar, Geração de Emprego e Renda no Estado do Ceará

sidades, ou como um processo de mudança na qual a exploração dos recursos, a orientação dos investimentos, os rumos do desenvolvimento tecnológico e a mudança institucional estão de acordo com as necessidades atuais e futuras (CMMAD, 1991).

Os conceitos de desenvolvimento sustentável pressupõem continuidade e permanência da qualidade de vida e da sociedade no longo prazo, caracterizados pela interação de quatro componentes: econômico, social, cultural e ambiental.

O econômico relaciona-se com a eficiência econômica e com o crescimento econômico, que são pré-requisitos fundamentais para a elevação da qualidade de vida com equidade. Esta é a condição necessária, mas não suficiente, do desenvolvimento sustentável. O segundo, social, tem como propósito a elevação da qualidade de vida e a equidade social, que são os objetivos centrais do modelo de desenvolvimento sustentável.

No terceiro componente, associado à questão cultural, pode ser inserida a variável capital social na perspectiva do "empowerment" coloca as pessoas e o poder no centro dos processos de desenvolvimento. É um processo pelo qual as pessoas, as organizações e as comunidades tomam o controle de seus próprios assuntos, de sua própria vida e tomam consciência da sua habilidade e competência para produzir, criar e gerir (ROMANO, 2002).

Já o quarto, ambiental, é o componente decisivo da sustentabilidade do desenvolvimento, pois a conservação ambiental permite a segurança da qualidade de vida das gerações futuras e equidade social sustentável e contínua ao longo do tempo.

O conceito da Comissão Brundtland, porém, não esclarece como vão ser satisfeitas as necessidades, nem sequer quais são essas necessidades ou de quais comunidades ou grupos sociais. As reflexões presentes no Relatório Brundtland e, em especial, o conceito de "desenvolvimento sustentável", serviram de fundamentação teórica para as principais propostas levadas à Conferência das Nações Unidas para o Meio Ambiente e Desenvolvimento (CNUMAD), realizada em 1992, no Rio de Janeiro.

4 O conceito de empowerment (literalmente, dotação de poder) etimologicamente alude a: permitir, capacitar, autorizar ou dar poder sobre algo a alguém ou para fazer algo. Conceitualmente, refere-se ao processo ou mecanismo através do qual pessoas, organizações ou comunidades adquirem controle ou domínio sobre assuntos ou temas de seu interesse. O conceito em nível comunitário centra-se na determinação social e se refere à possibilidade de participação democrática (no sentido de competência comunitária). Muitos estudos evidenciam o efeito positivo da sinergia entre Estado e sociedade civil. Como indicado por Durston (1999), em seu trabalho na Guatemala, a política pública pode contribuir para a formação e fortalecimento do capital social, empowerment, os setores sociais excluídos, ampliando o impacto dos serviços sociais sobre a base do compromisso da comunidade e dos agentes de desenvolvimento. 
Entre os diversos documentos internacionais assinados na conferência, destaca-se a "Agenda 21", elaborada como um plano de ação estratégica para o desenvolvimento sustentável global, tendo como signatários 174 chefes de governo. A "Agenda 21" apresenta-se como instrumento que tem como propósito "identificar atores, parceiros e metodologias para a obtenção de consensos e os mecanismosinstitucionais necessários para sua implementação e monitoramento".

Nos anos recentes, tanto no Brasil quanto no exterior, surgiram inúmeras políticas públicas valorativas da dimensão local, baseadas em estratégias de planejamento participativo, as quais gravitam em termo polifônico o ideário da sustentabilidade.

Neste sentido, não é difícil encontrar agentes públicos que fomentam processos "participativos" - quer seja por modismo, demagogia ou até por falta de clareza política - e que, no decorrer das discussões, perdem a condução política do processo frente às demandas da sociedade civil organizada.

Paralelamente, outras experiências, formalmente nomeadas como "Agenda 21 Local", podem significar um mero exercício de demagogia, representando, assim, pouco ou nenhum avanço em termos de inovação em políticas públicas. De modo geral, contudo, quando focada na esfera local - mesmo tendo em conta os limites de municípios ou até mesmo bairros - as experiências de planejamento e de intervenção possibilitam o surgimento de um campo fértil para a reflexão sobre a realidade, além de permitir, ao mesmo tempo, o afloramento e a canalização de esforços voltados à transformação desta realidade.

Diversos fatores fortalecem esta opção privilegiada pela ação local. O capítulo 40 da "Agenda 21" contém um plano de ação que abriga mais de 200 propostas de introdução de mudanças a partir de 1992, que foi reforçado pela terceira ${ }^{5}$ conferência sobre desenvolvimento sustentável (Rio +10$)$, realizada em agosto/ setembro de 2002, em Johanesburgo, África do Sul. Tal proposta, além de clamar pelo desenvolvimento de indicadores de sustentabilidade, tem a finalidade de fornecer subsídios à formulação de políticas estaduais e acordos internacionais, bem como à tomada de decisão por atores públicos e privados. Também busca conferir ao conceito de sustentabilidade maior concretude e funcionalidade.

\section{Metodologia}

\section{1. Área de Estudo e Fonte de Dados}

A presente pesquisa foi realizada com agricultores familiares beneficiários e não beneficiários do Pronaf B nos municípios de Baturité, Iguatu e Quixadá, no estado do Ceará.

5 A primeira conferência sobre desenvolvimento sustentável ocorreu em Estocolmo, Suécia, em 1972, e a segunda no Rio de Janeiro, em 1992 (Eco-92). 
136 - O Impacto do Pronaf sobre a Sustentabilidade da Agricultura Familiar, Geração de Emprego e Renda no Estado do Ceará

O município de Baturité situa-se no norte cearense, faz parte da macrorregião de planejamento de Baturité e encontra-se localizado a $79 \mathrm{~km}$ de Fortaleza, ocupando uma área geográfica de $308,78 \mathrm{~km}^{2}$. A população do município em 2007 era de 31.630 habitantes, sendo $27,68 \%$ residentes na zona rural (IPECE, 2007a, 2008).

O município de Iguatu situa-se no centro-sul cearense, faz parte da macrorregião de planejamento do Cariri/Centro Sul e encontra-se localizado a $306 \mathrm{~km}$ de Fortaleza, ocupando uma área geográfica de $1.029,00 \mathrm{~km}^{2}$. A população do município em 2007 era de 92.305 habitantes, sendo $24,38 \%$ residentes na zona rural. (IPECE, 2007b, 2008).

O município de Quixadá situa-se no sertão cearense, faz parte da macrorregião de planejamento do Sertão Central e encontra-se localizado a $147 \mathrm{~km}$ de Fortaleza, ocupando uma área geográfica de $2.019,82 \mathrm{~km}^{2}$. A população do município era de 76.114 habitantes em 2007 , sendo $30,36 \%$ residentes na zona rural. (IPECE, 2007c, 2008).

Este estudo foi realizado com base em dados primários oriundos da aplicação de questionários semiestruturados para informações qualitativas e quantitativas junto a 45 produtores beneficiários, incluídos na categoria B do Pronaf, e a 45 produtores não beneficiários do programa, selecionados aleatoriamente nos municípios de Baturité, Iguatu e Quixadá.

\subsection{Modelo Empírico}

\subsubsection{Procedimento Metodológico \\ para a Criação do Índice de Sustentabilidade (IS)}

Para a elaboração do índice de sustentabilidade da agricultura familiar nos municípios selecionados, foi necessária a elaboração de quatro índices adicionais (índice de desenvolvimento econômico-social, índice de capital social, índice ambiental e índice político-institucional), considerando-se um elenco de indicadores representativos dos mesmos.

Nesta visão, foi desenvolvido o seguinte Índice de Sustentabilidade:

$$
I S=\frac{1}{K} \sum_{h=1}^{k} I h
$$

Em que:

IS = Îndice de Sustentabilidade;

Ih = valor do h-ésimo índice;

$h=1, \ldots, k$ (índice).

$\mathrm{O}$ valor do h-ésimo índice foi calculado pela seguinte equação:

$I h=\frac{1}{S} \sum_{l=1}^{s} C_{l}$ 
A contribuição de cada indicador no Ih dos municípios foi obtida da seguinte maneira:

$$
C_{l}=\frac{1}{M} \sum_{j=1}^{m}\left[\frac{1}{n} \sum_{i=1}^{n}\left(\frac{E i j}{E \max i}\right)\right]
$$

Em que:

$C_{l}=$ contribuição do indicador " $l$ " no $l h$ dos agricultores familiares;

$E i j$ = escore da $i$-ésima variável do indicador "l" obtida pelo j-ésimo agricultor familiar;

$E$ max $i=$ escore máximo da $i$-ésima variável do indicador " $l$ ";

$i=1, \ldots, n$ (variáveis que compõem o indicador " $l$ ");

$j=1, \ldots, m$ (agricultores familiares);

$l=1, \ldots, s$ (indicadores que compõem o $l h$ ).

O valor do Índice de Sustentabilidade é a média aritmética dos quatro índices citados anteriormente; quanto mais próximo de 1, maior o nível de sustentabilidade dos agricultores familiares. O índice está situado dentro do intervalo $0 \leq$ IS $\leq 1$, sendo:

a) Baixo nível de sustentabilidade

$$
\begin{array}{r}
0 \leq \text { IS } \leq 0,5 \\
0,5<\text { IS } \leq 0,8 \\
0,8<\text { IS } \leq 1
\end{array}
$$

b) Médio nível de sustentabilidade

c) Alto nível de sustentabilidade

\subsubsection{1. Índice de Desenvolvimento Econômico-Social (IDES)}

A seguir são apresentadas as variáveis, com os seus respectivos escores, que fizeram parte dos indicadores utilizados para a aferição do índice de Desenvolvimento Econômico e Social. Foram considerados os seguintes indicadores: I) saúde; II) educação; III) habitação; IV) condições sanitárias e de higiene; V) lazer; VI) econômico.

\section{I) Indicador Saúde}

As condições de saúde podem refletir o impacto do Pronaf sobre a geração de renda e sobre o nível de investimento em capital humano, pois os indivíduos mais pobres apresentam maior probabilidade de adoecer. A perda de rendimento decorrente desse pior estado de saúde pode torná-lo ainda mais pobre.

Para este indicador, foi considerada a disponibilidade de serviços de saúde aos agricultores familiares e suas famílias, tais como:

a) Ausência de atendimento médico e ambulatorial 0

b) Atendimento de primeiros socorros $\quad 1$

c) Atendimento por agente de saúde 2

d) Atendimento médico 3 
138 - O Impacto do Pronaf sobre a Sustentabilidade da Agricultura Familiar, Geração de Emprego e Renda no Estado do Ceará

II) Indicador Educação

Para este indicador, foi considerada a existência ou ausência de serviços educacionais para os agricultores familiares e suas famílias, com os respectivos escores:

a) Ausência de escolas públicas ou comunitárias 0

b) Escolas de curso de alfabetização 1

c) Escolas de ensino fundamental 2

d) Escolas de ensino médio 3

e) Instituições de ensino superior 4

III) Indicador Habitacional

Foram considerados os seguintes aspectos habitacionais dos agricultores familiares: i) condição de domicílio; ii) tipo de construção de residência; iii) energia utilizada na residência.

III.1 - Condição de domicílio:
a) Alugada
b) Cedida
c) Própria

III.2 - Tipo de construção da residência:
a) Casa de taipa
b) Casa de tijolo, sem reboco e piso de terra 1
c) Casa de tijolo, com reboco e piso de cimento 2
d) Casa de tijolo, com reboco e piso de cerâmica 3

III. 3 - Iluminação utilizada na residência:

$\begin{array}{ll}\text { a) Lamparina e/ou velas } & 0 \\ \text { b) Lampião a querosene e/ou a gás } & 1 \\ \text { c) Energia elétrica } & 2\end{array}$

IV) Indicador Condições Sanitárias e Higiene

Este indicador foi elaborado com base em quatro variáveis: i) destino dado aos dejetos humanos; ii) origem da água para consumo humano; iii) tipo de tratamento dado à água para o consumo humano; iv) destino dado ao lixo domiciliar.

IV.1 - Destino dado aos dejetos humanos:

$\begin{array}{ll}\text { a) Jogado a céu aberto ou enterrado } & 0 \\ \text { b) Dirigido à fossa rudimentar } & 1 \\ \text { c) Dirigido à fossa séptica } & 2 \\ \text { d) Rede pública de esgoto } & 3\end{array}$ 
IV.2 - Origem da água para consumo humano:
a) Caminhão pipa
b) Diretamente do açude ou rio 1
c) Poço ou cacimba
d) Chafariz 3
e) Água encanada da rede pública

IV. 3 - Tipo de tratamento dado à água para consumo humano:

a) Nenhum tratamento 0

b) Fervida, filtrada ou com hipoclorito de sódio 1

IV.4 - Destino dado ao lixo domiciliar:

a) Jogado ao solo ou queimado

b) Enterrado

c) Recolhido através de coleta domiciliar 2

V) Indicador Econômico

Foi utilizada a renda anual da família (renda agropecuária + renda não agropecuária) como indicador econômico.

Os agricultores familiares foram divididos nos quatro grupos apresentados a seguir:

a) $\mathrm{R} \leq \mathrm{R} \$ 4.980,00$

b) $\mathrm{R} \$ 4.980,00<\mathrm{R} \leq \mathrm{R} \$ 9.960,00$

c) $\mathrm{R} \$ 9.960,00<\mathrm{R} \leq \mathrm{R} \$ 14.940,00$

d) $\mathrm{R}>14.940,00$

\section{VI) Indicador Lazer}

Concernente a este indicador, o agricultor familiar foi indagado a respeito do tipo de entretenimento disponível, considerando-se os seguintes escores:

a) Nenhuma infraestrutura de lazer

b) Barragem/balneário/rio ou salão de festa ou campo de futebol ou acesso à praia ou festas religiosas/populares

c) Duas opções pertencentes ao item b 2

d) Três opções pertencentes ao item b 3

e) Mais de três opções pertencentes ao item b

\subsubsection{2. Índice de Capital Social (ICS)}

O índice de capital social neste estudo foi elaborado a partir de indicadores que expressam as relações interpessoais dos agricultores familiares pesquisados.

A acumulação de capital social dos agricultores familiares nos municípios selecionados foi mensurada com base no Indice de Capital Social, resultante da agregação dos seguintes indicadores: 
140 - O Impacto do Pronaf sobre a Sustentabilidade da Agricultura Familiar, Geração de Emprego e Renda no Estado do Ceará

I) As pessoas sempre se interessam mais pelo seu bem-estar e de suas famílias, e não se preocupam muito com o bem-estar da comunidade?

(0) Sim

(1) Não

II) Quanta influência você acredita que tem para fazer da sua comunidade um local melhor para viver?

(0) Nenhuma influência

(1) Pouca influência

(2) Média influência

(3) Grande influência

As demais perguntas relativas aos indicadores que compõem o índice de capital social foram respondidas de acordo com o seguinte critério: (0) Não ou (1) Sim.

III) O (a) Sr. (Sra.) foi comunicado(a) e convidado(a) para assistir reuniões/ assembléias da associação?

IV) O (a) Sr. (Sra.) frequenta as reuniões da associação?

V) Todas as questões são respondidas em reuniões?

VI) O (a) Sr. (Sra.) participa da escolha dos líderes da associação?

VII) As decisões são aprovadas em reuniões/assembléias?

VIII) Nas reuniões, o (a) Sr. (Sra.) apresenta sugestões?

IX) As decisões tomadas são efetivamente executadas pela diretoria?

X) A associação realiza a prestação de contas com os associados?

XI) O (a) Sr. (Sra.) participa com cota (taxa)?

XII) O (a) Sr. (Sra.) participa na elaboração de eventos sociais?

XIII) Se o (a) Sr. (Sra.) tiver um problema, sempre aparecerá alguém para ajudar?

XIV) O (a) Sr. (Sra.) está satisfeito com o processo de escolha dos dirigentes?

XV) O (a) Sr. (Sra.) confia na maioria dos moradores da comunidade ou sócios da associação?

XVI) O (a) Sr. (Sra.) tem confiança nos líderes comunitários ou na maioria da diretoria da associação?

XVII) (a) Sr. (Sra.) tem confiança nas autoridades do seu município?

XVIII) O (a) Sr. (Sra.) tem confiança na sua própria capacidade para ajudar a resolver problemas de sua comunidade?

\subsubsection{3. Índice Ambiental (IA)}

Conforme Pereira (2001), uma justificativa para a utilização do indicador de sustentabilidade ambiental é a seguinte: a preservação e a recuperação do solo constituem uma questão básica, ou seja, qualquer atividade agrícola que 
destrua o solo, seja no curto ou longo prazo, não pode de forma alguma ser considerada uma atividade que esteja de acordo com o conceito e a prática de desenvolvimento sustentável.

A seguir é apresentada a relação dos indicadores que foram utilizados no cálculo do índice, com seus respectivos escores, para a aferição do Índice Ambiental.

I) Como é feita a conservação do solo?

(0) Não é realizada nenhuma prática de conservação

(1) Através de práticas mecânicas

(2) Através de práticas biológicas

II) Que método de controle de praga o (a) Sr. (Sra.) utiliza na unidade produtiva?

(0) Agrotóxico

(1) Nenhum método

(2) Biológico

III) Faz utilização de fogo nas atividades agropecuárias?

(0) Sim

(1) Não

IV) Qual é a intensidade do uso de agrotóxicos?

(0) 2 ou mais produtos

(1) 1 produto

(2) Nenhum produto

V) Qual é o destino dos restos das culturas?

(0) Queima

(1) Alimentação animal/venda a terceiros

(2) Incorporação ao solo após a colheita

As demais questões relativas aos indicadores que compõem o índice ambiental foram respondidas de acordo com o seguinte critério: (0) Não (1) Sim

VI) Faz plantio de árvore para fins de conservação de solos?

VII) Existe alguma área de reserva de mata nativa na propriedade?

VIII) A casa tem sistema de esgoto ou algum tipo de fossa?

IX) Faz rotação de cultura?

X) Se necessário, faz calagem?

XI) Faz análise de solo?

XII) Faz adubação verde?

XIII) Utiliza material orgânico?

XIV) Utiliza o solo de acordo com a sua vocação? 
142 - O Impacto do Pronaf sobre a Sustentabilidade da Agricultura Familiar, Geração de Emprego e Renda no Estado do Ceará

\subsubsection{4. Índice Político-Institucional (IPI)}

O Índice Político-Institucional caracteriza-se pela efetividade ou não de políticas públicas voltadas para os agricultores familiares, como, por exemplo: assistência técnica, difusão de tecnologias e crédito. Nesse contexto, foram observados os tipos de políticas públicas com os quais a agricultura familiar é contemplada e, ao mesmo tempo, se essas políticas são eficazes, eficientes e efetivas.

São apresentadas a seguir as questões relativas aos indicadores que compõem o índice político-institucional. As questões foram respondidas de acordo com o seguinte critério: (0) Não ou (1) Sim.

I) Recebeu assistência técnica pública?

II) Recebeu crédito de instituição pública?

III) Participou do Programa Hora de Plantar?

IV) Recebeu produtos e serviços oferecidos pelo escritório municipal de agricultura?

V) Participou de algum curso de capacitação?

VI) Recebeu tecnologias geradas ou apropriadas por instituições públicas?

\subsubsection{Análise do Efeito do Programa sobre a Renda}

\subsubsection{Renda Agropecuária}

O cálculo da diferença na renda agropecuária do beneficiário do Pronaf em relação à renda do não beneficiário foi realizado da seguinte forma:

$$
\begin{gathered}
\Delta R_{a g b}=\left(\sum_{g=1}^{c} P_{g b} A_{g b} Z_{g b}+\sum_{v=1}^{S} P_{v b} Q_{v b}\right)-\left(\sum_{g=1}^{c} P_{g n} A_{g n} A_{g n}+\sum_{v=1}^{S} P_{v n} Q_{v n}\right) \\
\Delta R_{a g b}=R_{a g b}-R_{a g n}
\end{gathered}
$$

Em que:

$P_{g b}=$ preço da cultura $g$ recebido pelo produtor beneficiário do Pronaf;

$P_{g n}=$ preço da cultura $g$ recebido pelo produtor não beneficiário do Pronaf;

$A_{g b}=$ área colhida da cultura $g$ pelo produtor beneficiário do Pronaf;

$A_{g n}=$ área colhida da cultura $g$ pelo produtor não beneficiário do Pronaf;

$Z_{g b}=$ produtividade da cultura $g$ obtida pelo produtor beneficiário do Pronaf;

$Z_{g n}=$ produtividade da cultura $g$ obtida pelo produtor não beneficiário do Pronaf;

$P_{v b}=$ preço do produto $v$ de origem pecuária recebido pelo beneficiário;

$Q_{v b}=$ quantidade produzida do produto $v$ de origem pecuária pelo beneficiário do Pronaf; 
$P_{v n}=$ preço do produto $v$ de origem pecuária recebido pelo não beneficiário do Pronaf;

$Q_{v n}=$ quantidade produzida do produto $v$ de origem pecuária pelo não beneficiário do Pronaf;

$R_{a g b}=$ renda agropecuária do beneficiário do Pronaf;

$R_{a g n}=$ renda não agropecuária do não beneficiário do Pronaf;

$\Delta R_{a g n}=$ diferença na renda agropecuária do produtor beneficiário;

$g=1,2, \ldots, c$ (culturas);

$v=1,2, \ldots, s$ (atividades de origem pecuária);

$b=1,2, \ldots, m$ (beneficiários);

$n=1,2, \ldots, d$ (não beneficiários)

\subsubsection{Renda Não Agropecuária}

A diferença na renda não agropecuária da família do beneficiário em relação à família do não beneficiário pelo Pronaf foi verificada pela seguinte equação:

$$
\begin{gathered}
\Delta R n a b=\sum_{k=1}^{s} R_{k b}-\sum_{k=1}^{s} R k n \\
\Delta R_{\text {nab }}=R_{\text {nab }}-R_{\text {nan }}
\end{gathered}
$$

Em que:

$R_{k b}=$ renda associada à atividade não agropecuária $k$ dos membros da família do beneficiário do Pronaf;

$R_{k n}=$ renda associada à atividade não agropecuária $k$ dos membros da família do não beneficiário do Pronaf;

$R_{n a b}=$ renda não agropecuária dos membros da família do beneficiário do Pronaf;

$R_{n a n}=$ renda não agropecuária dos membros da família do não beneficiário do Pronaf.

$k=1, \ldots, \mathrm{s}$ (atividades não agropecuárias).

\subsubsection{Renda Total}

A diferença na renda total da família do agricultor beneficiário em relação à família do agricultor não beneficiário pelo Pronaf foi dada pela seguinte equação:

$$
\Delta R_{t b}=\Delta R_{a g b}+\Delta R_{n a b}
$$


144 - O Impacto do Pronaf sobre a Sustentabilidade da Agricultura Familiar, Geração de Emprego e Renda no Estado do Ceará

\subsubsection{Renda Agropecuária por Hectare Cultivado}

A diferença na renda agropecuária por hectare cultivado do beneficiário do Pronaf em relação à renda do não beneficiário foi calculada pela seguinte equação:

$$
\begin{gathered}
\Delta R_{a g b h}=\frac{R_{a g b}}{\sum_{g=1}^{c} A_{g b}}-\frac{R_{a g n}}{\sum_{g=1}^{c} A_{g n}} \\
\Delta R_{a g b h}=R_{a g b h}-R_{a g h h}
\end{gathered}
$$

Em que:

$R_{a g b h}=$ renda agropecuária por hectare cultivado do beneficiário;

$R_{\text {agnh }}=$ renda agropecuária por hectare cultivado do não beneficiário.

A diferença na média da renda agropecuária por hectare cultivado dos beneficiários e não beneficiários foi obtida da seguinte forma:

$$
\begin{gathered}
\Delta \bar{R}_{a g b h}=\frac{1}{m} \sum_{b=1}^{m} R_{a g b h}-\frac{1}{d} \sum_{n=1}^{d} R_{a g n h} \\
\Delta \bar{R}_{a g b h}=\bar{R}_{a g b h}-\bar{R}_{a g h h}
\end{gathered}
$$

Em que:

$\overline{R_{a g b}}=$ média da renda agropecuária por hectare cultivado dos beneficiários;

$\overline{R_{a g n h}}=$ média da renda agropecuária por hectare cultivado dos não beneficiários.

\subsubsection{Análise do Efeito do Programa sobre o Emprego}

\subsubsection{Emprego Agropecuário}

O total de emprego agropecuário na propriedade do beneficiário do Pronaf foi determinado com base no trabalho requerido na área cultivada na propriedade, conforme descrito a seguir:

$$
E_{1 b}=\sum_{g=1}^{c} t_{g b} a_{g b}+\sum_{v=1}^{s} t_{v b}
$$

Em que:

$E_{1 b}=$ emprego agropecuário total na propriedade do beneficiário;

$t_{g b}=$ quantidade de mão de obra empregada por hectare da cultura $g$ na propriedade do beneficiário do Pronaf;

$a_{g b}=$ área cultivada da cultura $g$ na propriedade do beneficiário do Pronaf;

$t_{v b}=$ quantidade de mão de obra empregada na atividade pecuária $v$ na propriedade do beneficiário do Pronaf; 
O cálculo da diferença no trabalho total foi realizado tomando-se a diferença na mão de obra total empregada na propriedade dos beneficiários e não beneficiários do Pronaf, como escrito a seguir:

$$
\Delta E_{1}=\left(\sum_{b=1}^{m} \sum_{g=1}^{c} t_{g b} a_{g^{b}}-\sum_{n=1}^{d} \sum_{g=1}^{c} t_{g n} a_{g^{n}}\right)+\left(\sum_{b=1}^{m} \sum_{v=1}^{s} t_{v b}-\sum_{n=1}^{d} \sum_{v=1}^{s} t_{v n}\right)
$$

Em que:

$\Delta E_{1}=$ diferença no emprego agropecuário, na propriedade do beneficiário, resultante do Pronaf;

$t_{g b}, a_{g b}$ e $t_{v b}=$ descritos anteriormente;

$t_{g n}=$ quantidade de mão de obra empregada na cultura $g$ por hectare na propriedade do não beneficiário;

$a_{g n}=$ área cultivada da cultura $g$ na propriedade do não beneficiário;

$t_{v n}=$ quantidade de mão de obra empregada na atividade pecuária $v$ pelo não beneficiário;

$g=1, \ldots, c$ (culturas);

$v=1, \ldots, s$ (atividades pecuárias);

$b=1, \ldots, m$ (beneficiários do Pronaf);

$n=1, \ldots, d$ (não beneficiários do Pronaf).

\subsubsection{Emprego Agropecuário por Hectare}

Como foi observado no estudo que a área média cultivada pelos produtores beneficiários é bem inferior à área média cultivada pelos não beneficiários, e este fator pode influenciar a utilização de mão de obra nas propriedades, ocasionando um viés, o emprego total calculado foi dividido pela área total cultivada, de modo a obter-se o emprego agropecuário por hectare.

Para calcular o emprego agropecuário por hectare, considerou-se que o trabalhador trabalha oito horas por dia e 240 dias por ano. Utilizou-se ainda o coeficiente idade, com base no trabalho de Pereira (2007), sobre a agricultura familiar em Mato Grosso, descrito a seguir:

14 a 17 anos $=65 \%$ de homem/dia

18 a 60 anos $=100 \%$ de homem $/$ dia

Acima de 60 anos $=75 \%$ de homem/dia

Já o coeficiente sexo foi obtido do artigo de Silva e Kageyama (1983), no qual é apresentado o conceito de equivalente homem que, segundo os autores, representa a força de trabalho de um homem adulto ocupando todos os dias do ano. Sendo assim, para cada tipo de emprego, há um peso distinto para homens, mulheres e adolescentes, exibido a seguir:

Homem $=1$

Mulher $=0,66$

Adolescente $=0,4$ 
146 - O Impacto do Pronaf sobre a Sustentabilidade da Agricultura Familiar, Geração de Emprego e Renda no Estado do Ceará

A diferença na mão de obra por hectare cultivado na propriedade do beneficiário foi calculada pela seguinte equação:

$$
\begin{gathered}
\Delta E_{3}=\frac{E_{1 b}}{A_{t b}}-\frac{E_{1 n}}{A_{t n}} \\
\Delta E_{3}=E_{4}-E_{5}
\end{gathered}
$$

Em que:

$E_{1 b}=$ mão de obra agropecuária total empregada na propriedade do beneficiário do Pronaf;

$E_{1 n}=$ mão de obra agropecuária total empregada na propriedade do não beneficiário do Pronaf;

$A_{t b}=$ área total cultivada na propriedade do beneficiário;

$A_{t n}=$ área total cultivada na propriedade do não beneficiário;

$E_{4}=$ mão de obra agropecuária por hectare cultivado empregada na propriedade do beneficiário;

$E_{5}=$ mão de obra agropecuária por hectare cultivado empregada na propriedade do não beneficiário.

A diferença na média da mão de obra agropecuária por hectare cultivado empregada nas propriedades dos beneficiários e não beneficiários foi obtida como a seguir:

$$
\begin{gathered}
\Delta E_{6}=\frac{1}{m} \sum_{b=1}^{m} E_{4}-\frac{1}{d} \sum_{n=1}^{d} E_{5} \\
\Delta E_{6}=\bar{E}_{4}-\bar{E}_{5}
\end{gathered}
$$

Em que:

$\bar{E}_{4}=$ média da mão de obra agropecuária por hectare cultivado empregada nas propriedades dos beneficiários;

$\bar{E}_{s}=$ média da mão de obra agropecuária por hectare cultivado empregada nas propriedades dos não beneficiários.

\subsubsection{Comparação dos Agricultores Beneficiários e não Beneficiários do Pronaf}

Com o objetivo de realizar comparações entre os agricultores beneficiários e não beneficiários do Pronaf, foram realizados testes de hipótese, que variam de acordo com a natureza da variável analisada. Foi considerado o nível de significância de 5\%. A seguir, são apresentados os testes estatísticos adotados. 


\subsubsection{Teste " $t$ " de Student para Dados não Pareados}

O teste " $\mathrm{t}$ " de Student para dados não pareados é um teste paramétrico que permite comparar uma mesma variável em duas amostras diferentes, em um determinado instante. Foi empregado nas análises envolvendo variáveis quantitativas e com distribuição normal.

\subsubsection{Teste Qui-Quadrado para Independência ou Associação ( $\left.\chi^{2}\right)$}

Uma das importantes aplicações do teste qui-quadrado ocorre quando se deseja verificar a associação ou dependência entre duas variáveis qualitativas, diga-se $X$ e $Y$, ou quando se quer comparar dois grupos (caso deste estudo).

Um teste de homogeneidade ou aderência testa a hipótese nula de que um grupo A não difere de um grupo B quanto a uma determinada variável.

\subsubsection{Teste $U$ de Mann-Whitney}

Trata-se de um teste não paramétrico que pode ser aplicado para variáveis intervalares ou ordinais e é utilizado para verificar diferenças entre duas amostras independentes.

\section{Análise dos Resultados}

\section{1. Índice de Sustentabilidade}

Dada a importância da agricultura familiar para o desenvolvimento do País, é fundamental que este setor tenha condições de se desenvolver de forma sustentável.

As informações pertinentes à distribuição absoluta e relativa dos beneficiários e não beneficiários, segundo o IS, são apresentadas na Tabela 1.

Tabela 1. Frequência absoluta e relativa dos beneficiários e não beneficiários, segundo o IS, no estado do Ceará, 2008.

\begin{tabular}{ccccc}
\hline \multirow{2}{*}{ IS } & \multicolumn{2}{c}{ Beneficiários } & \multicolumn{2}{c}{ Não Beneficiários } \\
\cline { 2 - 5 } & $\begin{array}{c}\text { Frequência } \\
\text { Absoluta }\end{array}$ & $\begin{array}{c}\text { Frequência } \\
\text { Relativa }(\%)\end{array}$ & $\begin{array}{c}\text { Frequência } \\
\text { Absoluta }\end{array}$ & $\begin{array}{c}\text { Frequência } \\
\text { Relativa }(\%)\end{array}$ \\
\hline $0 \dashv 0,5$ & 24 & 53,3 & 41 & 91,1 \\
$0,5 \dashv 0,8$ & 21 & 46,7 & 4 & 8,9 \\
$0,8 \dashv 1$ & 0 & 0,0 & 0 & 0,0 \\
Total & 45 & 100,0 & 45 & 100,0 \\
Teste U de Mann-Whitney & \multicolumn{3}{c}{ Estatística do teste $=630,0$ Sig. $=0,000$} \\
\hline
\end{tabular}

Fonte: Dados da pesquisa. 
148 - O Impacto do Pronaf sobre a Sustentabilidade da Agricultura Familiar, Geração de Emprego e Renda no Estado do Ceará

Segundo os resultados, observa-se que a maioria dos produtores beneficiários $(53,3 \%)$ e não beneficiários $(91,1 \%)$ apresenta baixo nível de sustentabilidade. Por outro lado, $46,7 \%$ e 8,9\% dos beneficiários e não beneficiários, respectivamente, apresentam médio nível de sustentabilidade. Além disso, em nenhum dos grupos de produtores foi verificado alto nível de sustentabilidade. O valor do teste U de Mann-Whitney revela que a classificação do IS não é a mesma para beneficiários e não beneficiários.

Os dados relativos à participação absoluta e relativa do IDES, ICS, IA e IPI na composição do IS dos beneficiários e não beneficiários são apresentados na Tabela 2.

Observa-se que os valores absolutos de todos os índices que compõem o IS são maiores para os beneficiários. Os resultados evidenciam que as maiores contribuições na composição do IS dos beneficiários foram do IDES e do ICS. As maiores participações na composição do IS dos não beneficiários foram do IDES e do IA. Considerando-se o IS de cada grupo de produtores, verifica-se que os beneficiários e não beneficiários apresentam índices de 0,4649 e 0,3072, respectivamente. $\mathrm{O}$ resultado do teste t mostra que há diferença significativa no IS médio de beneficiários e não beneficiários.

Tabela 2. Participação do IDES, IA, ICS e IPI na composição do Índice de Sustentabilidade no estado do Ceará, 2008.

\begin{tabular}{ccccc}
\hline \multirow{2}{*}{ Índice } & \multicolumn{2}{c}{ Beneficiários } & \multicolumn{2}{c}{ Não Beneficiários } \\
\cline { 2 - 5 } & Valor Absoluto & Valor Relativo (\%) & Valor Absoluto & Valor Relativo (\%) \\
\hline IDES & 0,1426 & 30,6774 & 0,1406 & 45,7594 \\
IA & 0,0841 & 18,0914 & 0,0786 & 25,5738 \\
ICS & 0,1345 & 28,9355 & 0,0723 & 23,5471 \\
IPI & 0,1037 & 22,3011 & 0,0157 & 5,1196 \\
IS & 0,4649 & 100,0 & 0,3072 & 100,0 \\
Teste T para o IS & \multicolumn{4}{c}{ t $=5,581$ g.l. = 88 Sig. $=0,000$} \\
\hline
\end{tabular}

Fonte: Dados da pesquisa.

O IDES calculado em ambos os grupos foi relativamente superior aos demais índices utilizados. No índice em questão, os indicadores de menor relevância foram lazer, renda das famílias e acesso aos serviços de educação, tanto nos grupos de beneficiários quanto no grupo de não beneficiários.

Os baixos valores observados no índice de sustentabilidade ambiental nos grupos de beneficiários e não beneficiários podem ser atribuídos a práticas agrícolas inadequadas como: não realização de análises de solo e de calagem, o não uso de adubação verde, ausência de métodos de controle de pragas e doenças, bem como de conservação de solo. 
O capital social, avaliado por meio do ICS (Índice de Capital Social), mostrouse baixo em ambos os grupos, no entanto, no grupo dos não beneficiários foram identificadas fragilidades maiores, o que pode ser uma consequência do baixo nível de influência dos agricultores nas decisões tomadas pela associação da qual participam, desinteresse dos dirigentes destas associações em relação ao bemestar da comunidade, ausência de participação dos associados na organização de eventos sociais, e baixo nível de confiança entre os associados.

Quanto ao índice de sustentabilidade político-institucional, o baixo valor verificado nos grupos dos não beneficiários pode ser associado ao não recebimento de assistência técnica, dificuldades de acesso ao crédito, indisponibilidade de tecnologias adequadas e baixa participação em cursos de capacitação.

\subsection{Efeito do Programa sobre a Renda}

A Tabela 3 expõe as informações sobre frequência absoluta e relativa dos beneficiários e não beneficiários segundo a renda agropecuária anual. De acordo com os dados apresentados, a maioria dos beneficiários (93,3\%) e não beneficiários $(80,0 \%)$ possui uma renda agropecuária anual de até $\mathrm{R} \$$ 4.980,00. Observa-se ainda que nenhum beneficiário tem renda agropecuária anual superior a $\mathrm{R} \$ 9.960,00$, enquanto dois não beneficiários detêm renda agropecuária anual superior a $\mathrm{R} \$ 14.940,00$. O resultado do teste U de MannWhitney mostra que não há diferença entre as faixas de renda agropecuária anual de beneficiários e não beneficiários.

Tabela 3. Frequência absoluta e relativa dos beneficiários e não beneficiários segundo a renda agropecuária anual no estado do Ceará, 2008.

\begin{tabular}{ccccc}
\hline \multirow{2}{*}{$\begin{array}{c}\text { Renda } \\
\text { Agropecuária Anual }\end{array}$} & \multicolumn{2}{c}{ Beneficiários } & \multicolumn{2}{c}{ Não Beneficiários } \\
\cline { 2 - 5 } & $\begin{array}{c}\text { Frequência } \\
\text { Absoluta }\end{array}$ & $\begin{array}{c}\text { Frequência } \\
\text { Relativa (\%) }\end{array}$ & $\begin{array}{c}\text { Frequência } \\
\text { Absoluta }\end{array}$ & $\begin{array}{c}\text { Frequência } \\
\text { Relativa (\%) }\end{array}$ \\
\hline$\leq 4.980,00$ & 42 & 93,3 & 36 & 80,0 \\
$4.980,00 \dashv 9.960,00$ & 3 & 6,7 & 6 & 13,3 \\
$9.960,00 \dashv 14.940,00$ & 0 & 0,0 & 1 & 2,2 \\
$>14.940,00$ & 0 & 0,0 & 2 & 4,4 \\
Total & 45 & 100,0 & 45 & 100,0 \\
Teste U de Mann-Whitney & \multicolumn{4}{c}{ Estatística do teste $=873,0$ Sig. $=0,056$} \\
\hline
\end{tabular}

Fonte: Dados da pesquisa.

Segundo os dados da Tabela 4, verifica-se que $68,9 \%$ dos beneficiários e $57,8 \%$ dos não beneficiários têm renda não agropecuária anual de até $R \$ 4.980,00$. Observa-se também que 4,4\% dos produtores de cada grupo têm renda não agropecuária anual superior a $\mathrm{R} \$ 14.940,00$. Com base no valor do teste $\mathrm{U}$ de 
150 - O Impacto do Pronaf sobre a Sustentabilidade da Agricultura Familiar, Geração de Emprego e Renda no Estado do Ceará

Mann-Whitney, pode-se inferir que não há diferença entre as faixas de renda não agropecuária anual de beneficiários e não beneficiários.

Tabela 4. Frequência absoluta e relativa dos beneficiários e não beneficiários segundo a renda não agropecuária anual no estado do Ceará, 2008.

\begin{tabular}{ccccc}
\hline \multirow{2}{*}{$\begin{array}{c}\text { Renda Não } \\
\text { Agropecuária Anual }\end{array}$} & \multicolumn{2}{c}{ Beneficiários } & \multicolumn{2}{c}{ Não Beneficiários } \\
\cline { 2 - 5 } & $\begin{array}{c}\text { Frequência } \\
\text { Absoluta }\end{array}$ & $\begin{array}{c}\text { Frequência } \\
\text { Relativa (\%) }\end{array}$ & $\begin{array}{c}\text { Frequência } \\
\text { Absoluta }\end{array}$ & $\begin{array}{c}\text { Frequência } \\
\text { Relativa (\%) }\end{array}$ \\
\hline$\leq 4.980,00$ & 31 & 68,9 & 26 & 57,8 \\
$4.980,00 \dashv 9.960,00$ & 8 & 17,8 & 14 & 31,1 \\
$9.960,00 \dashv 14.940,00$ & 4 & 8,9 & 3 & 6,7 \\
$>14.940,00$ & 2 & 4,4 & 2 & 4,4 \\
Total & 45 & 100,0 & 45 & 100,0 \\
Teste U de Mann-Whitney & \multicolumn{5}{c}{ Estatística do teste $=921,0$ Sig. $=0,388$} \\
\hline
\end{tabular}

Fonte: Dados da pesquisa.

As informações sobre a renda agropecuária anual média, renda total anual média e média da renda agropecuária anual por hectare cultivado são apresentadas na Tabela 5. De acordo com os resultados, a renda agropecuária anual média e a renda familiar total anual média dos não beneficiários são maiores do que as dos beneficiários. Esses resultados são explicados, em parte, pelo tamanho médio da propriedade dos não beneficiários, quase três vezes maior que o tamanho médio da propriedade dos beneficiários. Os resultados do teste $t$ mostram que a renda agropecuária anual média e a renda total anual média não são as mesmas para beneficiários e não beneficiários.

Tabela 5. Teste t para diferença entre as médias de renda anual de beneficiários e não beneficiários no estado do Ceará, 2008.

\begin{tabular}{lcccc}
\hline \multicolumn{1}{c}{ Renda } & Benef. (R\$) & Não Benef. (R\$) & Estatística t & Sig. \\
\hline Renda agropecuária anual média & $2.144,44$ & $4.455,51$ & $-2,302$ & 0,026 \\
Renda familiar total anual média & $7.101,8$ & $9.982,71$ & $-2,018$ & 0,047 \\
$\begin{array}{l}\text { Média da renda agropecuária } \\
\text { anual por ha cultivado }\end{array}$ & 1518,75 & $1.207,61$ & 0,919 & 0,361 \\
\hline
\end{tabular}

Fonte: Dados da pesquisa.

Para eliminar o efeito do tamanho da propriedade, foi calculada a média da renda agropecuária anual por hectare cultivado. Dessa forma, pode-se observar que a média da renda agropecuária anual por hectare cultivado dos beneficiários $(\mathrm{R} \$ 1.518,75)$ é superior à média dos não beneficiários (R\$ 1.207,61). O resultado 
do teste t revela que a média da renda agropecuária anual por hectare cultivado é a mesma para beneficiários e não beneficiários.

Estudos realizados por Kageyama (2003) e Dias et al. (2006) mostraram que o Pronaf não causou impacto positivo significante sobre a renda dos beneficiários, enquanto as pesquisas da Fecamp (2002) e de Magalhães et al. (2005) revelaram resultados negativos em termos de impacto.

A Tabela 6 apresenta a distribuição absoluta e relativa dos beneficiários e não beneficiários segundo as principais fontes de renda não agropecuária. Conforme evidenciam os dados, nota-se que $28,9 \%$ dos beneficiários e 55,6\% dos não beneficiários recebem aposentadoria, o que explica, parcialmente, a superioridade da renda familiar total anual média dos não beneficiários em relação à dos beneficiários. O valor do teste qui-quadrado revela que não há diferença entre os grupos quanto ao recebimento de aposentadoria.

Tabela 6. Frequência absoluta e relativa dos beneficiários e não beneficiários segundo as principais fontes de renda não agropecuária no estado do Ceará, 2008.

\begin{tabular}{|c|c|c|c|c|c|}
\hline \multirow[b]{2}{*}{ Variável } & \multirow[b]{2}{*}{ Resposta } & \multicolumn{2}{|c|}{ Beneficiários } & \multicolumn{2}{|c|}{ Não Beneficiários } \\
\hline & & $\begin{array}{c}\text { Frequência } \\
\text { Absoluta }\end{array}$ & $\begin{array}{c}\text { Frequência } \\
\text { Relativa (\%) }\end{array}$ & $\begin{array}{c}\text { Frequência } \\
\text { Absoluta }\end{array}$ & $\begin{array}{l}\text { Frequência } \\
\text { Relativa (\%) }\end{array}$ \\
\hline \multirow{3}{*}{$\begin{array}{l}\text { Aposenta- } \\
\text { doria }\end{array}$} & Sim & 13 & 28,9 & 25 & 55,6 \\
\hline & Não & 32 & 71,1 & 20 & 44,4 \\
\hline & Teste Qui-Quadrado & \multicolumn{4}{|c|}{ Estatística do teste $=6,559$ g.l. $=1$ Sig. $=0,010$} \\
\hline \multirow{3}{*}{ Bolsa-Família } & Sim & 31 & 68,9 & 18 & 40,0 \\
\hline & Não & 14 & 31,1 & 27 & 60,0 \\
\hline & Teste Qui-Quadrado & \multicolumn{4}{|c|}{ Estatística do teste $=7,571$ g.l. $=1$ Sig. $=0,006$} \\
\hline \multirow{3}{*}{ Comércio } & Sim & 10 & 22,2 & 5 & 11,1 \\
\hline & Não & 35 & 77,8 & 40 & 88,9 \\
\hline & Teste Qui-Quadrado & \multicolumn{4}{|c|}{ Estatística do teste $=2,000$ g.l. $=1$ Sig. $=0,157$} \\
\hline \multirow{3}{*}{$\begin{array}{l}\text { Trabalho } \\
\text { Permanente }\end{array}$} & Sim & 9 & 20,0 & 6 & 13,3 \\
\hline & Não & 36 & 80,0 & 39 & 86,7 \\
\hline & Teste Qui-Quadrado & \multicolumn{4}{|c|}{ Estatística do teste $=0,720$ g.l. $=1$ Sig. $=0,396$} \\
\hline \multirow{3}{*}{$\begin{array}{l}\text { Trabalho } \\
\text { Temporário }\end{array}$} & Sim & 13 & 28,9 & 7 & 15,6 \\
\hline & Não & 32 & 71,1 & 38 & 84,4 \\
\hline & Teste Qui-Quadrado & \multicolumn{4}{|c|}{ Estatística do teste $=2,314$ g.l. $=1$ Sig. $=0,128$} \\
\hline
\end{tabular}

Fonte: Dados da pesquisa.

Em relação ao recebimento de Bolsa-Família, observa-se que 68,9\% dos beneficiários recebem este auxílio, enquanto $60 \%$ dos não beneficiários não o recebem. O valor do teste qui-quadrado mostra que há diferença entre os grupos quanto ao recebimento do Bolsa-Família. 
152 - O Impacto do Pronaf sobre a Sustentabilidade da Agricultura Familiar, Geração de Emprego e Renda no Estado do Ceará

Também é possível verificar que 22,2\% e 11,1\% dos beneficiários e não beneficiários, respectivamente, realizam atividades relacionadas ao comércio. O resultado do teste qui-quadrado evidencia que não há diferença entre os grupos quanto à realização de atividades de comércio.

A maioria dos beneficiários e não beneficiários não possui trabalho permanente nem realiza trabalho temporário. $\mathrm{O}$ valor do teste qui-quadrado mostra que não há diferença entre os grupos quanto a esta variável.

\subsection{Efeito do Programa sobre o Emprego}

De acordo com os dados da Tabela 7, a mão de obra total média empregada nas atividades agropecuárias nas propriedades dos beneficiários é maior quando comparada com a média dos não beneficiários. O teste $t$, no entanto, indica que não há diferença significativa entre a mão de obra total média empregada nas atividades agropecuárias nas propriedades dos beneficiários e dos não beneficiários. É importante ressaltar que uma parte substancial das propriedades dos não beneficiários é utilizada para atividades pecuárias que necessitam relativamente de uma quantidade de mão de obra menor em relação às atividades agrícolas.

Comparando-se a média da mão de obra familiar empregada por hectare, observa-se que os beneficiários geram 1,32 emprego, enquanto os não beneficiários criam somente 0,37 emprego. $\mathrm{O}$ resultado do teste $\mathrm{t}$ sugere que existe diferença significativa na média da mão de obra familiar empregada nas atividades agropecuárias por hectare nas propriedades de beneficiários e não beneficiários.

Tabela 7. Teste t para diferença entre as médias de mão de obra empregada nas propriedades dos beneficiários e não beneficiários no estado do Ceará, 2008.

\begin{tabular}{lcccc}
\hline \multicolumn{1}{c}{ Mão de Obra } & Beneficiários & Não Beneficiários & Estatística t & Sig. \\
\hline $\begin{array}{l}\text { Média da mão de obra total empregada } \\
\text { nas atividades agropecuárias }\end{array}$ & 1,69 & 1,42 & 1,202 & 0,232 \\
$\begin{array}{l}\text { Média da mão de obra familiar empre- } \\
\text { gada nas atividades agropecuárias por } \\
\text { hectare cultivado }\end{array}$ & 1,32 & 0,37 & 3,049 & 0,004 \\
$\begin{array}{l}\text { Média da mão de obra total empregada } \\
\text { nas atividades agropecuárias por hectare } \\
\text { cultivado }\end{array}$ & 1,52 & 0,46 & 3,104 & 0,003 \\
\hline
\end{tabular}

Fonte: Dados da pesquisa.

Em relação à comparação da média da mão de obra total por hectare cultivado, verifica-se que a média de utilização da mão de obra nas propriedades dos beneficiários é maior que a média dos não beneficiários. Com base no valor 
do teste $t$, pode-se afirmar que há diferença significativa entre os valores médios de mão de obra total por hectare empregada nas propriedades de beneficiários e não beneficiários.

\section{Conclusões e Sugestões}

Com base nos resultados encontrados no presente estudo, conclui-se que a categoria dos beneficiários e não beneficiários apresenta médio nível de desenvolvimento econômico-social. Os indicadores saúde e habitação apresentaram as maiores contribuições ao IDES dos beneficiários e não beneficiários, enquanto os indicadores de menor participação no IDES foram o lazer e o econômico, tanto para beneficiários quanto para não beneficiários.

O grupo dos beneficiários apresenta médio nível de acumulação de capital social. O grupo dos não beneficiários, por sua vez, apresenta baixo nível de acumulação de capital social.

O baixo nível de preservação ambiental das categorias dos beneficiários e não beneficiários demonstra que os mesmos seguem práticas pouco sustentáveis, evidenciando que a preservação dos recursos ambientais exige maior atenção por parte das instituições de apoio e orientação aos produtores.

O grupo dos beneficiários apresenta médio nível de acesso às políticas públicas. A categoria dos não beneficiários, por sua vez, apresenta baixo nível de acesso às políticas públicas.

Tanto o grupo dos beneficiários quanto o dos não beneficiários apresentam baixo nível de sustentabilidade. No entanto, os valores absolutos dos índices que compõem o Índice de Sustentabilidade dos beneficiários são maiores que os respectivos valores obtidos pelos não beneficiários.

Os produtores beneficiários e não beneficiários, em sua maioria, têm renda agropecuária anual de até $\mathrm{R} \$ 4.980,00$. O Bolsa-Família e a aposentadoria são as fontes de renda de destaque entre os beneficiários e não beneficiários, respectivamente.

A renda agropecuária anual média e a renda total anual média das famílias dos não beneficiários são superiores às das famílias dos beneficiários. Por outro lado, a renda agropecuária anual por hectare cultivado média dos beneficiários é superior à dos não beneficiários.

As médias da mão de obra familiar empregada nas atividades agropecuárias por hectare cultivado e da mão de obra total empregada nas atividades agropecuárias por hectare cultivado dos beneficiários são superiores às médias dos não beneficiários. A média da mão de obra total empregada nas atividades agropecuárias dos beneficiários é superior à média dos não beneficiários.

O Pronaf B nos municípios de Baturité, Iguatu e Quixadá está sendo operado de forma genérica, sem levar em consideração o contexto de desenvolvimento de cada uma dessas regióes (disponibilidade de escolas, postos de saúde, estradas, 
154 - O Impacto do Pronaf sobre a Sustentabilidade da Agricultura Familiar, Geração de Emprego e Renda no Estado do Ceará

transportes, telecomunicações etc.) que, evidentemente, não está sob o controle das unidades de produção, mas afeta significativamente o desempenho dos produtores.

Assim, considera-se que devem ser implementadas políticas educacionais básicas que proporcionem aos produtores maior nível educacional, fator de extrema importância, tanto para a absorção de conhecimentos e práticas tradicionais de cultivo e criação, como para a adoção de novas tecnologias e viabilização do uso de técnicas de gestão. A educação ambiental também é um importante instrumento a ser implantado, a fim de conscientizar agricultores a respeito das consequências relacionadas à degradação do meio ambiente, o que pode contribuir para a obtenção de maior nível de preservação ambiental.

O poder público deve realizar investimentos no sentido de melhorar as condições de saúde e o estado nutricional dos agricultores e de suas famílias que, aliado aos investimentos educacionais, possibilitam maior acumulação de capital humano por parte dos agricultores. Além disso, é essencial a canalização de recursos para o desenvolvimento de infraestrutura produtiva nas localidades em que o estudo foi realizado. Assim como o nível educacional, a existência de infraestrutura física é fator fundamental para viabilizar a adoção de pacotes tecnológicos modernos.

De modo a minimizar a desarmonia entre a política de crédito e os demais componentes da política agrícola, é essencial a implementação de uma política fundiária e a melhoria da abrangência e da qualidade do serviço de assistência técnica. A mudança da condição fundiária da maioria dos beneficiários pode proporcionar maior estímulo para a realização de investimentos em tecnologia, aumentando a produtividade das atividades agropecuárias e, consequentemente, a renda dos produtores.

\section{Referências Bibliográficas}

ALTAFIN, I. G. Sustentabilidade, políticas públicas e agricultura familiar: uma apreciação sobre a trajetória brasileira. 2003. $225 \mathrm{f}$. Tese (Doutorado) - Centro de Desenvolvimento Sustentável, Universidade de Brasília, Brasília, 2003.

BUAINAIN, A. M. Agricultura familiar, agroecologia e desenvolvimento sustentável: questões para debate. Brasília: IICA, 2006.

CMMAD - Comissão Mundial sobre Meio Ambiente e Desenvolvimento. Nosso Futuro Comum. 2 ed. Rio de Janeiro: Fundação Getúlio Vargas, 1991.

DIAS, F. M. et al. A experiência recente do PRONAF em Pernambuco: uma análise por meio de propensity score. Economia Aplicada, Ribeira Preto, vol. 10, n. 1, 2006. 
DURSTON, John. Construyendo Capital Social Comunitário: Uma Experiência de Empoderamiento Rural em Guatemala. Santiago del Chile: CEPAL, 1999.

FECAMP - Fundação de Economia de Campinas. Convênio PCT/IICA-PRONAF. Estudos de Caso em Campo para Avaliação dos Impactos do PRONAF. Campinas, outubro/2002. Disponível em: http://www.pronaf.gov.br.

GUANZIROLI, C. E. PRONAF dez anos depois: resultados e perspectivas para o desenvolvimento rural. Revista de Economia e Sociologia Rural, Rio de Janeiro, vol. 45, n. 02, p. 301-328, abr/jun. 2007.

IPECE - INSTITUTO DE PESQUISA E ESTRATÉGICA ECONÔMICA DO CEARÁ. Perfil básico municipal: Baturité. 2007a. Disponível em: <http:www.ipece. ce.gov.br>. Acesso em 20 dez. 2008.

. Perfil básico municipal: Iguatu. 2007b. Disponível em: <http://www.ipece. ce.gov.br>. Acesso em: 20 dez. 2008.

. Perfil básico municipal: Quixadá. 2007c. Disponível em: <http://www. ipece.ce.gov.br>. Acesso em: 20 dez. 2008.

. Anuário Estatístico do Ceará 2007. 2008. Disponível em: < http://www2. ipece.ce.gov.br>. Acesso em: 20 dez. 2008.

JARA, C. J. Planejamento do desenvolvimento municipal com participação de diferentes atores sociais. Centro de Estudos da Fundação Konrad-Adenauer-Stiftung, Ação Local e Desenvolvimento Sustentável, Caderno Debates, n. 11, São Paulo, 1996.

KAGEYAMA, A. Produtividade e renda na agricultura familiar: efeitos do PRONAF crédito. Agricultura em São Paulo, São Paulo: IEA, v. 50, n. 2, p. 1-13, 2003.

LIMA NETO, P. C. Extensão rural e agricultura familiar. 1999. Disponível em: $<$ http://www.faser.org.br/artigoExtensaoruraleagriculturafamiliar.doc $>$. Acesso em: 10 fev. 2007.

MAGALHÃES, A. M. et al. The family farm program in Brazil: the case of Pernambuco. In: CONGRESSO DA SOCIEDADE BRASILEIRA DE ECONOMIA E SOCIOLOGIA RURAL, 18., 2005, Ribeirão Preto. Anais... Ribeirão Preto: SOBER, 2005.

Ministério do Desenvolvimento Agrário - MDA. Perguntas e Respostas sobre o PRONAF. 2005. Disponível em: < http://www.mda.gov.br/saf/index.php?sccid=1243>. Acesso em: 27 dez. 2008.

PEREIRA, A. C. Programa Nacional de Microcrédito Produtivo Orientado (PNMPO): Descrição, Resultados e Perspectivas. Porto Alegre, RS - Junho, 2007. 
156 - O Impacto do Pronaf sobre a Sustentabilidade da Agricultura Familiar, Geração de Emprego e Renda no Estado do Ceará

PRONAF - PROGRAMA NACIONAL DE FORTALECIMENTO DA AGRICULTURA FAMILIAR. Relatório institucional. Publicação do Ministério do Desenvolvimento Agrário. Brasília: MDA-SAF-PRONAF, 2002. 8 p.

RABELO, L. S. Indicadores de sustentabilidade: a possibilidade do desenvolvimento sustentável. Fortaleza: Prodema, UFC, 2008.

ROMANO, J. O. "Empowerment": enfrentaremos primeiro a questão do poder para combater juntos a pobreza. Internacional Workshop "empowerment" and Rights Based Approach in Fighting poverty together, Rio de Janeiro, Brasil $4^{\text {th }}$ to $6^{\text {th }}$ September 2002.

SILVA, J. G.; KAGEYAMA, A. Emprego e relação de trabalho na agricultura brasileira: Uma análise dos dados censitários de 1960, 1970 e 1975. Pesquisa e Planejamento Econômico, Rio de Janeiro, v.13, n.1, p. 235-266, abr. 1983. 